\title{
SHOPPING VALUE, TRUST, AND ONLINE SHOPPING WELL-BEING: A DUALITY APPROACH
}

\author{
Ho Trong Nghia \\ International School of Business, University of Economics Ho Chi Minh City, Ho Chi Minh City, Vietnam
}

\section{Svein Ottar Olsen}

School of Business and Economics, UiT Arctic University of Norway, Tromso, Norway, and

\section{Nguyen Thi Mai Trang}

School of Management, University of Economics Ho Chi Minh City, Ho Chi Minh City, Vietnam

Published in Marketing Intelligence \& Planning, Vol. 38 No 5, 2020, pp. 545-558

DOI: 10.1108/MIP-08-2019-0411 


\begin{abstract}
Purpose - Based on a duality approach, this study examines the path from utilitarian value via cognitive trust versus hedonic value via affective trust in online shopping well-being. This study also explores the moderating role of extraversion in the relationships between shopping value and trust.
\end{abstract}

Design/methodology/approach - A data set collected from 648 online consumers in Vietnam was used to validate the measures employing confirmatory factor analysis (CFA) and to test the hypotheses using Structural Equation Modelling (SEM).

Findings - The results show that online shopping well-being is determined hedonically and affectively rather than utilitarian and cognitively. Affective trust positively contributes to online shopping well-being, but cognitive trust does not. The dual-process associations between utilitarian shopping value and cognitive trust and between hedonic shopping value and cognitive trust were also confirmed. Finally, extraversion moderates the cognitive and affective associations between shopping values and trust.

Originality/value - This study contributes to the literature on online shopping by applying a dual perspective to confirm the role of hedonic shopping value and affective trust in positively determining online shopping well-being. As a result, this study provides a deeper understanding about if and why online shopping well-being is affect based, instead of cognition based.

Key words: Shopping well-being; Shopping value; Trust; Duality approach; Online shopping; Vietnam. 


\section{Introduction}

The topic of subjective well-being has received much attention of consumer researchers in which studying shoppers' subjective well-being based on their shopping activities has recently emerged as an area of great interest (e.g. Ekici et al., 2018). Shopping is considered as a "necessary and an inevitable activity" of human life (Ekici et al., 2018, p. 335) and its positive contribution has been widely acknowledged such as pleasure and arousal (Liao et al., 2016) or satisfaction (Kesari and Atulkar, 2016). These positive consequences contribute significantly to shoppers' overall quality of life, which is best represented by the concept of shopping well-being (Ekici et al., 2018).

Note that the duality approach considering two different mental systems - cognition and affect - has been widely applied in consumer research (e.g. Chen and Lee, 2008; Hofmann et al., 2009; Watson et al., 1988). This approach has been used to investigate positive and negative affect (Watson et al., 1988), hedonic versus utilitarian shopping motivation (Babin et al., 1994), hedonic and utilitarian dimensions of consumer attitudes (Voss et al., 2003) and impulse buying and self-control (Hofmann et al., 2009). The approach has also helped to explain how hedonic and utilitarian shopping values influence online shopping preferences, attitudes, intentions, engagement or behaviour (Chen and Lee, 2008; Overby and Lee, 2006). The literature has indicated that shopping activities are both work and fun (Babin et al., 1994) or hedonic and utilitarian (Hirschman and Holbrook, 1982). In other words, consumers are driven by both utilitarian and hedonic shopping values and, thus, shopping decisions are made based not only on rational deliberations for maximizing cost-benefit efficiency or product utility, but also on emotional benefits like playfulness or pleasure. These cognitive and affective benefits of shopping significantly contribute to consumers' shopping well-being (El Hedhli et al., 2016). However, to the best of our knowledge, the duality approach has not been adopted to study shopping well-being as an outcome of shopping value, especially in the online shopping context.

The literature has indicated that online shopping is characterized by inherent risks (Ariffin et al., 2018; Kim and Koo, 2016), and lack of trust is one of the biggest barriers to online purchasing (e.g. Beldad 
et al., 2010). It is also problematic that there is no universally accepted definition for online trust, which is considered to be multi-faceted and incorporates different dimensions across different research disciplines (e.g. Punyatoya, 2019). Further, almost all previous studies of trust in e-commerce have focused on how trust influences online attitudes, satisfaction, intention and behavioural loyalty indicators (Kim and Peterson, 2017). This study contributes to the existing literature on online shopping by studying the impacts of dual trust (cognitive and affective) on online shopping well-being.

As previously noted, online shopping well-being may be significantly determined by shopping values and trust. However, studies on the associations between shopping values and trust have been inconclusive and require further evaluation (Beldad et al., 2010). In the extant literature, trust is mainly considered as a determinant of shopping values (e.g. Chai et al., 2015), which has led to a lack of studies examining the predicting role of shopping values for trust. Existing research has noted that treating different facets of values as antecedents of trust is a possibility (see Kim and Peterson, 2017 for a recent review). Different theoretical perspectives are also used in different research disciplines such as philosophy, psychology, management, or marketing to study shopping values and trust (Beldad et al., 2010; Punyatoya, 2019). For example, Chiu et al. (2014) use a mean-end chain theory and argue that utilitarian and hedonic values are the final goals that trigger online intention and behaviour. Other studies (e.g. Chen and Lee, 2008; Al-Debei et al., 2015) use a value-attitude-behaviour (VAB) framework positing that online shopping values flow through attitudes that influence behaviour. Following this approach, this study argues that trust is a mediator between shopping values and online shopping wellbeing.

The predictive role of the Big Five personality traits has been strongly validated in consumer research (e.g. Choi et al., 2015; Costa and McCrae, 1992; Ul Islam et al., 2017). Besides, the moderating role of consumers' personalities has been investigated in the offline purchasing context (e.g. Menidjel et al., 2017). Unfortunately, to the best of our knowledge, this role of consumer traits has seldom been examined in the online shopping context, especially on the association between online shopping values and 
trust. Note that among the Big Five personalities, extraversion is a significant factor explaining online consumer beliefs toward hedonic value (e.g. Chen and Lee, 2008). Furthermore, extraversion is the most important trait predicting consumer engagement in online brand communities and determines online shopping intention (Ul Islam et al., 2017).

This study adopts the duality approach and focuses on the online shopping context of an emerging economy - Vietnam - to: (1) examine the cognitive and affective associations between shopping values and trust; (2) investigate the influences of cognitive and affective trust on online shopping well-being; and (3) explore the moderating role of extraversion on the dual relationships between shopping values and trust. Using Structural Equation Modelling (SEM), this study validates the dual associations between shopping values and trust that, in turn, positively predict online shopping well-being. The remainder of the paper presents the theoretical background, hypotheses, research method, data analysis, and results followed by discussions and implications.

\section{Background and Literature Review}

The positive consequence of online shopping: Online shopping well-being

Subjective well-being has been studied across several research approaches. From the perspective of hedonism, subjective well-being reflects a situation in which an individual evaluates all aspects of his or her life positively in a cognitive and/or affective manner (Diener et al., 1985). Thus, subjective well-being is considered the individual's satisfaction with life and is measured by the Satisfaction with Life Scale (Diener et al., 1985). However, Pavot and Diener (2008) argue that satisfaction with life solely represents the cognitive aspect, while the affective aspect also contributes to subjective well-being. Specifically, these authors identify three main components of subjective well-being: life satisfaction, the presence of positive affect or mood and the absence of negative affect or mood. 
In a more specific approach to the individual's shopping life, El Hedhli et al. (2013) discuss the construct of shopping well-being, which reflects the contribution of shopping to shoppers' overall sense of well-being. Recently, the contribution of shopping has been clearly classified into positive and negative (Ekici et al., 2018). The authors define shopping well-being as the degree to which shopping contributes positively to consumers' quality of life, whereas shopping ill-being refers to the negative effects of shopping activity. Although shopping activity may result in even opposite outcomes (e.g. Ekici et al., 2018), the positive consequences of shopping have been repeatedly echoed in the extant literature. For instance, shopping contributes to pleasure and arousal (Liao et al., 2016), hedonic enjoyment (Babin et al., 1994), satisfaction (Kesari and Atulkar, 2016) and flow (Bilgihan, 2016). Based on the approach of Ekici et al. (2018), this study considers online shopping well-being as the positive contribution of online shopping to online shoppers' quality of life.

Existing shopping well-being research has determined some key predictors, including external factors (e.g. store layout or stock-outs), social or cultural attitudes, values, personality or self-related factors (El Hedhli et al., 2013; Lee and Sirgy, 2004). Among these factors, shopping values serve as strong possible determinants of shopping well-being. El Hedhli et al. (2016) provide strong evidence to support the significant influence of shopping values on shopping well-being in the mall shopping context. Unfortunately, to the best of our knowledge, this association has seldom been explored in the online shopping context. This study therefore examines online shopping well-being as the consequence of dual shopping values (utilitarian and hedonic) in the online shopping context.

\section{Dual shopping values: Utilitarian and hedonic value}

During the shopping process, shoppers are driven by both the products and emotional attractions (Chen and Wang, 2016). In other words, consumers go shopping for both utilitarian and hedonic value. Utilitarian value consists of the cognitive benefits characterized by consumers' conscious pursuit of an intended consequence, while hedonic value refers to affective states (e.g. fun, playfulness) that may result from making a purchase. Hirschman and Holbrook (1982) indicate that, along with primary utilitarian benefits, 
consumers also have a demand for feeling, aesthetics, emotion and enjoyment. Voss et al. (2003) classify consumer attitudes into utilitarian and hedonic dimensions, which reflect the functions performed by the product and the sensation of experiencing the product, respectively. The significance of these dual shopping values has been highlighted in several recent studies (e.g. Giovanis and Athanasopoulou, 2017; Sarkar et al., 2018; Varshneya et al., 2017).

The extant literature has shown that hedonic versus utilitarian shopping values, identified by the duality approach, are used to explain both offline (Kesari and Atulkar, 2016) and online (Chiu et al., 2014) shopping motivations and behaviour. For example, Batra and Ahtola (1991, p. 159) argue that "consumers purchase goods and services and perform consumption behaviours for two basic reasons: (1) consummatory affective (hedonic) gratification (from sensory attributes), and (2) instrumental, utilitarian reasons concerned with expectations of consequences". Thus, in the online shopping context, this study considers utilitarian and hedonic shopping values as cognitive and affective benefits of online shopping.

\section{The dual perspective of trust: Cognitive and affective trust}

Trust reflects an individual's willingness to depend on the behaviours of the partner in a relationship and is a multi-faceted attitude construct (e.g. Beldad et al., 2010; Ha et al., 2016). In fact, researchers have widely agreed that trust has two distinctive forms: cognition-based and affect-based trust (McAllister, 1995; Morrow et al., 2004); trust is a dual construct consisting of a cognitive and an affective component (Ha et al., 2016). Applying this approach to shopping activity, the first component, cognitive trust, reflects consumers' confidence that retailers are "honest, accurate, and dependable, and keeps promises" (Dabholkar et al., 2009, p. 149). In fact, trust is formed based on consumers' rational expectations, whereas positive affect reflecting the emotional attachment between buyers and providers also builds trust (Punyatoya, 2019). The second component, affective trust, refers to the positive feeling consumers have during an experience with the retailers (Johnson and Grayson, 2005).

In the online shopping context, consumers inherently face risks caused by the uncertain behaviours of e-tailers and/or the uncertain environment (Kim and Koo, 2016). For instance, risks related to payment, 
product, information, time and psychology impact online shoppers' purchase intention negatively (Ariffin et al., 2018). Fortunately, trust not only significantly reduces perceived risks (Kim and Koo, 2016), but also leverages online consumers' purchase intention, satisfaction or loyalty (Kim and Peterson, 2017). Thus, trust is critically important for online consumers. Adopting the duality perspective, trust reflects the willingness of online consumers to be cognitively and affectively dependent on e-tailers. Specifically, cognitive trust is formed based on online consumers' rational evaluations of e-tailers, including the assessment of reputation (Mansour et al., 2004). Affective trust is the online shoppers' emotional base that increases their positive perception about the e-tailers' trustworthiness (McCole et al., 2010). In this study, cognitive and affective trust are considered two separate components of online consumers' willingness to be dependent on e-tailers.

\section{Moderator: Extraversion}

Personality traits determine a person's cognitive, affective and behavioural styles (Ul Islam et al., 2017). Among the Big Five traits, extraversion refers to an individual's interests in social interactions (e.g. Choi et al., 2015; Costa and McCrae, 1992), thus extroverts are characterised as sociable, talkative, active and enthusiastic. In the online shopping context, extraversion is a prominent factor explaining consumers' shopping values, attitudes and behaviours (Chen and Lee, 2008; Ul Islam et al., 2017). For instance, extraverted consumers are more critical in searching for hedonic shopping values that, in turn, result in a positive attitude toward online shopping (Chen and Lee, 2008). Further, among personality traits, extraversion has the strongest influence on consumer engagement in an online brand community, leading to more online purchase intention (Ul Islam et al., 2017). Thus, online consumers' expected shopping values and attitudes may vary due to their extraversion. Consequently, extraversion is potentially a significant factor moderating the cognitive and affective associations between shopping values and trust in the online shopping context. 


\section{Model Development and Research Hypotheses}

\section{Conceptual model}

Drawing upon the duality approach in the online shopping context, this study explores the dual associations between shopping values and trust. Specifically, cognitive trust in online retailers may be predicted mainly by utilitarian value, whereas hedonic value primarily influences consumers' affective trust. Both cognitive and affective components of trust are hypothesized to positively affect online shopping well-being. Extraversion is proposed as a moderator of the dual associations between shopping values and trust. The conceptual model presented in Figure 1 illustrates these relationships.

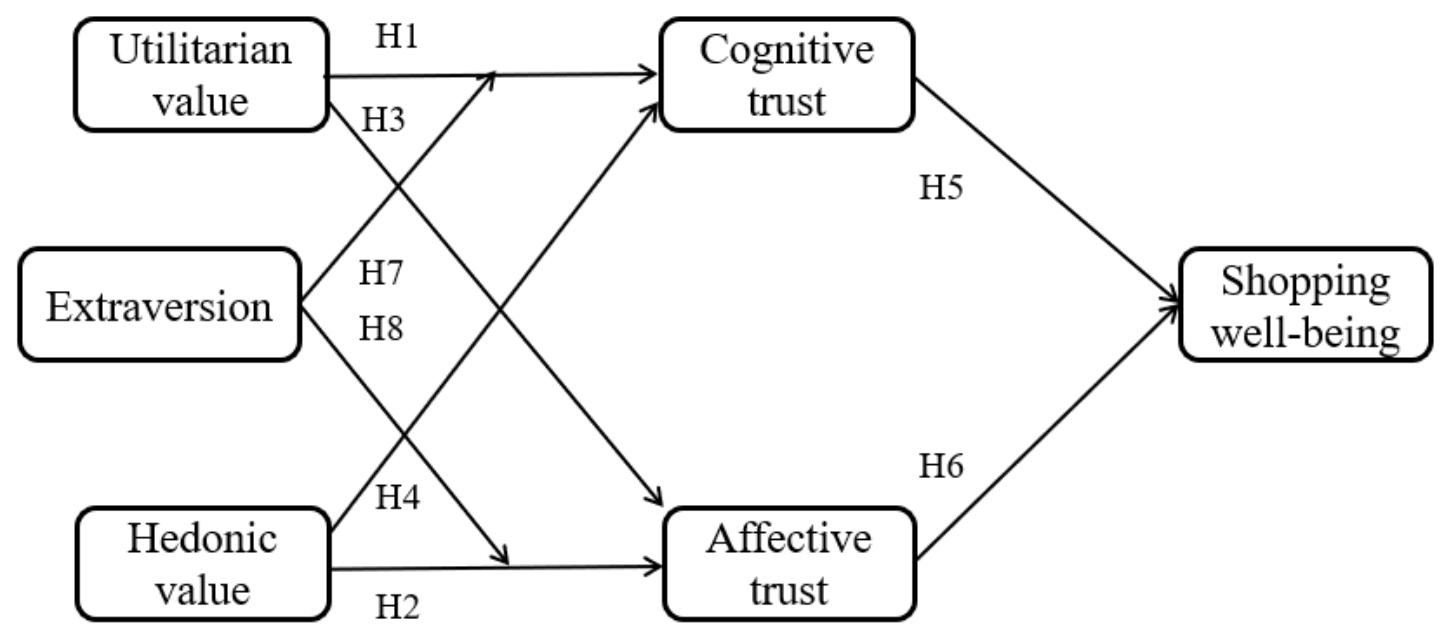

Figure I. Conceptual model

\section{Research hypotheses}

The associations between online shopping values and trust have been underlined by the VAB framework (Homer and Kahle, 1988), which argues for close connections between individuals' values and attitudes. These authors assert that the values people pursue drive how they perceive and, ultimately, behave in certain circumstances. Adapting this logic to the online shopping context, consumer attitudes about etailers potentially depend on shopping values. Both utilitarian and hedonic features of a retailing website can increase online shoppers' trust (Bilgihan, 2016). Similarly, the associations between shopping values and trust have been supported by a recent meta-analysis (Kim and Peterson, 2017) in which online 
consumers' trust in e-tailers can be significantly determined by different values (e.g. perceived quality or usefulness). Within the duality approach, it can therefore be proposed that utilitarian values enhance online consumers' cognitive trust, whereas hedonic values are positively associated with online consumers' affective trust.

Although the cognitive and affective components of a construct may highly correlate with each other, they are different in how they predict or are influenced by other factors and behaviour (e.g. Crites et al., 1994). This is because cognitive linkages are cognition-based, whereas affective associations are emotion-driven. Even when including both the cognitive and affective component of a construct in a research model, researchers may wish to consider them separately (Herbst et al., 2003). In this study, the cross-over effects of shopping values and online consumer trust (i.e. utilitarian value-affective trust, and hedonic value-cognitive trust) are proposed to be non-significant. The associations between shopping values and trust, based on the duality approach, in online shopping are therefore hypothesized as follows:

H1. Utilitarian value positively affects cognitive trust

H2. Hedonic value positively affects affective trust

H3. The impact of utilitarian value on affective trust is non-significant

H4. The impact of hedonic value on cognitive trust is non-significant In online shopping, trust is a crucial factor that positively influences consumers' evaluations of their online purchases (Kim and Peterson, 2017). Online shoppers with a higher level of trust perceive online shopping to be more beneficial (e.g. Kim et al., 2012). Similarly, online shopping is also considered positive in terms of both cognitive and affective aspects of trust (Ha et al., 2010), and more trust is associated with reduced risk and more transaction intention (Kim and Koo, 2016). Furthermore, satisfaction and loyalty are prominent outcomes of online trust (Kim and Peterson, 2017), implying that once trust has been successfully built, online shopping becomes more advantageous to online consumers. In other words, trust can cognitively and affectively leverage the extent to which online shopping positively determines 
consumers' quality of life. Therefore, adopting the duality approach, this study proposes that cognitive and affective trust significantly contribute to online shopping well-being.

H5. Cognitive trust positively affects online shopping well-being

H6. Affective trust positively affects online shopping well-being

Extraversion determines the extent to which an individual is interested in social interactions and looks for excitement and stimulation (e.g. Choi et al., 2015; Costa and McCrae, 1992). Although previous studies have largely adopted extraversion as a determinant (e.g. Ul Islam et al., 2017), its moderation on the associations between shopping values and trust attitude in the online shopping context is highly potential. Extraverted consumers are recreational shoppers who are more interested in hedonic values such as entertainment or enjoyment (Chen and Lee, 2008). Compared to other traits in the well-known Big Five, extraversion is the most influential factor determining consumer engagement in online brand communities, which in turn determines online purchase intention (U1 Islam et al., 2017). Further, extraversion is a significant emotion-related factor (Watson and Clark, 1997) explaining online consumer attitudes toward hedonic value (e.g. Chen and Lee, 2008). Being emotion-driven, extraverted consumers prefer to look for hedonic value, which positively predicts affective trust. Consequently, extraversion can leverage the extent to which hedonic value affects consumers' affective trust in e-tailers. In addition, although risks are inherent in the online shopping context (e.g. Kim and Koo, 2016), extroverts are risk-takers (Nicholson et al., 2005) who are less concerned with such threats. Thus, online shoppers who are extroverts are more willing to be cognitively dependent on e-tailers. Therefore, extraversion can also leverage the extent to which utilitarian value affects online consumers' cognitive trust. Based on these arguments, this study proposes that the cognitive and affective associations between shopping values and trust are moderated by extraversion. Specifically,

H7. Extraversion positively moderates the impact of utilitarian value on cognitive trust.

H8. Extraversion positively moderates the impact of hedonic value on affective trust. 


\section{Research Methods}

\section{Research context}

The Vietnamese e-commerce market has reached a high growth rate of over $25 \%$ in 2017 that is estimated to remain high in following years (Vietnam E-business Index, 2018). In this context, the growth rate of business-to-consumer (B2C) sales remarkably reached 35\% in 2017. Thus, online shopping has been widespread and become a popular shopping channel for Vietnamese consumers. Based on the E-Business Index report, Ho Chi Minh City (HCMC) is the leader among all provinces and cities of Vietnam in terms of the B2C component index in 2017 (Vietnam E-business Index, 2018). This indicates that the consumers in HCMC are quite familiar with online purchasing.

\section{Procedure and sample}

A self-administered survey using convenience sampling was conducted in HCMC - Vietnam. Specifically, a hard copy of the questionnaire was delivered to consumers. A screening question was included for selecting appropriate respondents (i.e., online consumers had purchased at least once in three months). A total of 950 questionnaires were distributed and 872 online consumers responded, resulting in a response rate of $91.80 \%$. This preliminary data set was then refined and 224 questionnaires were excluded due to missing more than $10 \%$ of values. The final dataset, including 648 completed questionnaires, was used for further analysis. This sample consisted of $65.70 \%$ females and $34.30 \%$ males. Most of the participants were between 25 and 40 years of age, accounting for $51.10 \%$ of respondents, while $46.70 \%$ participants were 25 years old or younger and $2.20 \%$ of participants were over 40 years of age. This survey data were employed to validate the measures via confirmatory factor analysis (CFA) and to test the model and hypotheses by SEM. 


\section{Measurement}

This study adopted existing validated measures that were unidimensional for all constructs, including utilitarian value, hedonic value, cognitive trust, affective trust, online shopping well-being and extraversion. Dual shopping values were measured by scales borrowed from Voss et al. (2003): five items for utilitarian value and six items for hedonic value. Cognitive and affective trust were measured by five items each, adopted from Dabholkar et al. (2009). Online shopping well-being was measured by three items adopted from Ekici et al. (2018). Extraversion was measured by eight items, based on BenetMartínez and John (1998). A 7-point Likert-type scale (1, strongly disagree, and 7, strongly agree) was used for the items measuring cognitive trust, affective trust and online shopping well-being. A 7-point semantic differential scale was used for items measuring utilitarian shopping value, hedonic shopping value and extraversion. These items were randomly placed in the questionnaire. The use of different scaling methods and random assignments sought to reduce the agreement bias tendency.

\section{Data Analysis and Results}

\section{Measurement validation}

CFA was employed to validate the measures, and the results indicated that the saturated model yielded an acceptable fit to the data: $\chi^{2}(\mathrm{df}=379)=690.53, \chi^{2} / \mathrm{df}=1.82(\mathrm{p}<.001), \mathrm{GFI}=.94, \mathrm{CFI}=.98, \mathrm{TLI}=.97$ and RMSEA $=.04$, and all items possessed high CFA factor loadings $(\lambda \geq .59 ; \mathrm{p}<.001 ;$ See Table I). The average variance extracted (AVE) of constructs was also high (AVE $\geq .50)$, except for affective trust (AVE $=.49)$. Note that an item measuring utilitarian value was deleted due to its low factor loadings $(\lambda<.50)$. Thus, the constructs' unidimensionality and convergent validity were achieved. Table II shows the details for the construct discriminant validity test, where the AVE for each construct in any pair of constructs was higher than the corresponding correlation (Fornell and Larcker, 1981). 
Table I. Standardized CFA loadings $(\lambda)$ of items

\begin{tabular}{|c|c|}
\hline Item & Factor loading \\
\hline \multicolumn{2}{|l|}{ Hedonic value: $\mathrm{CR}=.91 ; \mathrm{AVE}=.63$} \\
\hline Dull/exciting & .81 \\
\hline Not delightful/delightful & .87 \\
\hline Enjoyable/unenjoyable & .90 \\
\hline Not playful/playful & .85 \\
\hline Amusing/not amusing & .62 \\
\hline Not sensuous/sensuous & .68 \\
\hline \multicolumn{2}{|l|}{ Utilitarian value: $\mathrm{CR}=.87 ; \mathrm{AVE}=.63$} \\
\hline Effective/ineffective & .66 \\
\hline Helpful/unhelpful & .84 \\
\hline Functional/not functional & .90 \\
\hline Handy/not handy & .75 \\
\hline \multicolumn{2}{|l|}{ Cognitive trust: $\mathrm{CR}=.90 ; \mathrm{AVE}=.65$} \\
\hline \multicolumn{2}{|l|}{ In my opinion, $\mathrm{X}$ is an online retailer that... } \\
\hline Provides accurate information & .76 \\
\hline Keeps the promises & .74 \\
\hline Provides consistent services and quality & .81 \\
\hline Is very dependable & .86 \\
\hline Is sincere & .87 \\
\hline \multicolumn{2}{|l|}{ Affective trust: $\mathrm{CR}=.83 ; \mathrm{AVE}=.49$} \\
\hline In all circumstances, $\boldsymbol{X}$ is ready to offer me assistance and support & .63 \\
\hline When providing products and services, $X$ is concerned about my welfare & .78 \\
\hline I trust $X$ because it seems to care about me & .79 \\
\hline I can depend on $\mathrm{X}$ to buy important things & .69 \\
\hline In general, $\mathrm{X}$ is willing to serve its customers & .59 \\
\hline \multicolumn{2}{|l|}{ Shopping well-being: $\mathrm{CR}=.80 ; \mathrm{AVE}=.57$} \\
\hline I feel that online shopping contributes significantly to my own personal well-being & .75 \\
\hline I feel that online shopping makes me happy & .79 \\
\hline I feel that online shopping contributes significantly to my quality of life overall & .73 \\
\hline \multicolumn{2}{|l|}{ Extraversion: $\mathrm{CR}=.91 ; \mathrm{AVE}=.55$} \\
\hline \multicolumn{2}{|l|}{ I see myself as someone who... } \\
\hline Is outgoing, sociable & .78 \\
\hline Is talkative & .67 \\
\hline Has an assertive personality & .68 \\
\hline Generates a lot of enthusiasm & .75 \\
\hline Is full of energy & .80 \\
\hline Is reserved & .73 \\
\hline Is sometimes shy, inhibited & .77 \\
\hline Tends to be quiet & .73 \\
\hline
\end{tabular}


Table II. Correlation (r) between and Average variance extracted (AVE) for constructs Notes: Values on the diagonal are AVEs; *Significant at $p<.01 ;$ NS: non-significant

\begin{tabular}{|llcccccc|}
\hline & & $\mathbf{1}$ & $\mathbf{2}$ & $\mathbf{3}$ & $\mathbf{4}$ & $\mathbf{5}$ & $\mathbf{6}$ \\
\hline $\mathbf{1}$ & Hedonic Value & $\mathbf{. 6 3}$ & & & & & \\
2 & Utilitarian Value & $.60^{*}$ & .63 & & & & \\
$\mathbf{3}$ & Cognitive Trust & $.14^{*}$ & $.15^{*}$ & .65 & & & \\
$\mathbf{4}$ & Affective Trust & $.25^{*}$ & $.18^{*}$ & $.56^{*}$ & .49 & & \\
$\mathbf{5}$ & Shopping Well-being & $.16^{*}$ & $-.01^{\mathrm{NS}}$ & $.19^{*}$ & $.37^{*}$ & .57 & \\
$\mathbf{6}$ & Extraversion & $.57^{*}$ & $.51^{*}$ & $.18^{*}$ & $.20^{*}$ & $.09^{\mathrm{NS}}$ & $\mathbf{. 5 5}$ \\
\hline
\end{tabular}

\section{Common method bias}

The participants completed all questions at the same time through a self-report method that allowed for the possibility of common method bias (Podsakoff et al., 2003). To minimize this bias, in the design phase, the constructs were measured with either a Likert-type or semantic differential scale randomly placed in the questionnaire, and the construct "novelty seeking" was also included in the questionnaire as a marker variable.

Three different tests were conducted to examine whether common method bias was a major issue in the research: CFA Harman's single-factor test, marker variable analysis and t-test of mean difference. First, the CFA single-factor model yielded a very poor fit to the data $\left(\chi^{2} /(\mathrm{df}=393)=4001.22, \chi^{2} / \mathrm{df}=10.18\right.$, $\mathrm{GFI}=.68, \mathrm{CFI}=.71, \mathrm{TLI}=.66$ and RMSEA $=.12)$ compared to the trait factor model $\left(\chi^{2}(\mathrm{df}=379)=690.53\right.$, $\chi^{2} / \mathrm{df}=1.82, \mathrm{GFI}=.94, \mathrm{CFI}=.98, \mathrm{TLI}=.97$ and RMSEA $\left.=.04\right)$. Second, the difference of the correlation estimates of the constructs before and after including the marker was .002 . This result provides evidence that the marker did not account for the correlations between constructs (Lindell and Whitney, 2001). Third, t-test analysis comparing the correlations of the two models (e.g. with and without the marker) revealed that there was no difference $(p>.97)$. These results indicate that even if a common method bias were present, it did not pose a serious threat in this study. 


\section{Hypothesis testing}

In this study, extraversion was proposed as a moderator to the cognitive and affective associations between shopping values and trust. A single-step estimation approach that was considered more conceptually and operationally straightforward (Cortina et al., 2001) was therefore adopted. Two interaction terms were first calculated by multiplying mean-deviated values of the corresponding constructs (utilitarian value and hedonic value by extraversion) to avoid multicollinearity (Cronbach, 1987). These interactions were then included in the SEM model, and all variables were analysed simultaneously. Maximum likelihood estimates for structural paths are shown in Table III.

Table III. Structural paths

Note: $\beta$ : Standardized estimate

\begin{tabular}{|clcc|}
\hline Hypothesis & Structural paths & $\beta$ & $p$-value \\
\hline H1 & Utilitarian value $\rightarrow$ Cognitive trust & .19 & .001 \\
H2 & Hedonic value $\rightarrow$ Affective trust & .28 & .00 \\
H3 & Utilitarian value $\rightarrow$ Affective trust & .06 & .28 \\
H4 & Hedonic value $\rightarrow$ Cognitive trust & .07 & .20 \\
H5 & Cognitive trust $\rightarrow$ Shopping well-being & .01 & .83 \\
H6 & Affective trust $\rightarrow$ Shopping well-being & .39 & .00 \\
H7 & Utilitarian value x Extraversion $\rightarrow$ Cognitive trust & .16 & .00 \\
H8 & Hedonic value x Extraversion $\rightarrow$ Affective trust & .21 & .00 \\
\hline
\end{tabular}

The SEM results indicate that the proposed model showed acceptable fit to the data: $\chi^{2}(242)=703.21$ $(\mathrm{p}=.000), \mathrm{GFI}=.92, \mathrm{CFI}=.95, \mathrm{TLI}=.94$ and $\mathrm{RMSEA}=.05$. The results also suggest that all hypotheses were statistically significant, except for H5. Specifically, H1, proposing a positive relationship between utilitarian value and cognitive trust, was supported $(\mathrm{p}<.001)$. The positive impact of hedonic value on affective trust was also significant ( $\mathrm{p}<.001$ ), supporting H2. For both $\mathrm{H} 3$ and H4, the estimates were not statistically significant $(\mathrm{p}>.26$ and $\mathrm{p}>.20)$, reflecting no associations between utilitarian value and affective trust or between hedonic value and cognitive trust. The positive influence of affective trust on online shopping well-being was also found, supporting H6 $(\mathrm{p}<.001)$. The effect of the interaction between 
utilitarian value and extraversion on cognitive trust was significant ( $<.001)$, supporting H7. Similarly, H8, which proposed a moderating effect of extraversion on the association between hedonic value and affective trust was validated due to a significant $\mathrm{p}$-value $(\mathrm{p}<.001)$. Finally, the proposed influence of cognitive trust on online shopping well-being was not supported. Thus, H5 was rejected.

\section{Discussion and Implications}

Adopting the duality approach, in the online shopping context, this study examined the effects of shopping values on trust which, in turn, influenced online shopping well-being of consumers; and tested the moderating role of extraversion on shopping values - trust associations. First, the findings revealed that utilitarian and hedonic shopping values are positive determinants of the cognitive and affective trust, respectively. Generally, how online shopping is favourably evaluated is dependent on the benefits consumers gaining from e-tailers. These results are consistent with previous research (e.g. Bilgihan, 2016; Kim and Peterson, 2017) and contribute to a more thorough understanding of the shopping values - trust relationships. Second, although affective trust was shown to be a positive and significant influencer of online shopping well-being, cognitive trust was not. Therefore, online shopping well-being is determined affectively rather than cognitively; it is worth noting that online shopping well-being has rarely been examined as the consequence of trust in the extant literature. Third, extraversion positively moderated the dual associations between shopping values and trust. This finding is somewhat consistent with the previous study of Chen and Lee (2008). Finally, this study significantly contributes to the related theory and practice.

\section{Implications for theory}

Theoretically, the research findings contribute to the existing consumer value-attitude literature (Chen and Lee, 2008; Chiu et al., 2014; Overby and Lee, 2006) by digging deeper into the processes between 
shopping values and trust of online consumers. First, utilitarian value enhances cognitive trust and hedonic value positively influences affective trust. This highlights the cognitive and affective effects of shopping values on trust in online shopping. Note that while the general value-attitude link has been widely accepted, the duality approach has rarely been adopted in studying it. These findings therefore serve as initial evidence supporting the dual associations between shopping values and trust. The research results also show that while utilitarian value positively predicts cognitive trust, it does not influence affective trust. Similarly, hedonic value helps to increase affective trust, but does not affect cognitive trust. These results indicate that shopping values influence trust via separate processes - either cognitive or affective validating the dual associations between them. Related studies have neither clarified the cognitive and affective associations between utilitarian and hedonic benefit and trust (Bilgihan, 2016) nor investigated the direct relationship between utilitarian value and hedonic value and trust. This study therefore establishes the duality approach for the associations between shopping values and trust both theoretically and empirically.

Second, in the online shopping context, while consumer trust produces many positive outcomes (e.g. Kim and Koo, 2016; Kim and Peterson, 2017), how it affects online shopping well-being remains unclear. This gap has initially been addressed, as this study revealed a significantly positive relationship between affective trust and online shopping well-being. This strengthens the significance of the hedonic or affective aspect, rather than the utilitarian or cognitive aspect, of shopping activity. In other words, the "fun" side of shopping enhances the extent to which online shopping positively contributes to consumers' quality of life. As a result, this study sheds new light and significantly contributes to the extant literature on online shopping well-being.

The moderating role of extraversion has also been validated. For a more extraverted consumer, the impact of utilitarian shopping value on his or her cognitive trust and of hedonic shopping value on his or her affective trust has been strengthened. While this role of extraversion has rarely been investigated in 
existing studies, the present result provides direct evidence to highlight the significance of the extraversion trait, especially in online shopping.

\section{Implications for practice}

The findings of this study provide valuable insights for policy makers and practitioners in the e-commerce industry. For e-tailers, the results identified that affective trust plays a significant role in enhancing online consumers' shopping well-being. Thus, e-retailing managers should build their consumers' affective trust, for instance, by showing their care and willingness in serving their consumers. Besides, they need to assist and support their consumers in a timely manner. These help to show their concern about consumers' welfare. Second, this study found that hedonic shopping value enhances affective trust in online shopping. Therefore, e-tailers should also pay attention to increase the hedonic benefits provided to online shoppers. For instance, they may design a rich and immersive retailing website for creating memorable and meaningful shopping experiences to online consumers. Automatically informing the status of the purchased orders via cell phone or email can be another solution for increasing the hedonic or entertainment value for online consumers. In doing so, consumers are likely to immerse themselves in hedonically enjoyable shopping activities to fulfil their meaningful goals (Sirgy et al. 2016). This fosters consumers' shopping-life balance, leading to higher consumer quality of life (Eikici et al., 2018). Further, e-tailers also need to ensure the utilitarian values for consumers, for example, by ensuring products' quality and/or providing competitive price. These benefits help to level up consumers' trust in online shopping.

E-tailers might also be encouraged to make use of online consumers' extraversion because it can leverage the dual impacts of shopping values on trust. While shopping values are less effective in increasing the trust attitudes of more introverted consumers, e-tailers need supplementary actions to increase these consumers' level of trust. Using social networks, for example, to spread positive information may be an effective solution (e.g. Ha et al., 2016). 
For consumer advocacy organisations and policy makers, the findings of this study suggest that educational programmes providing online consumers with knowledge about financial literacy and the shortcomings of over-indebtedness are necessary for enhancing consumers' shopping-life balance. This will assist consumers in overcoming overspending or distress in online shopping. In addition, policy makers may issue official regulations for better facilitating online B2C retailing. For example, a standard set for retailing website can help to ensure website quality that significantly impacts consumers' online buying behaviour (Akram et al., 2018). If this is the case, e-tailers know clearly how their retailing websites should be, whereas online shoppers can gain benefits by purchasing with those standard-complied websites. Thus, these solutions make online channel more beneficial for both shoppers and e-tailers.

\section{Limitations and Future Directions}

A limitation of this study is the consideration of online shopping well-being only under the predictive role of cognitive and affective trust. It could be helpful to examine other predictors on shopping well-being in order to better understanding the conditions of promoting shopping well-being. For instance, website attributes enhance the levels of satisfaction and purchase intention (Hsu et al., 2012), thus, potentially determine online shopping well-being. Future studies to re-examine the association between cognitive trust and online shopping well-being are also recommended. This may help confirm or refute the impact of cognitive trust on online shopping well-being in the context of online shopping. 


\section{References}

Akram, U., Hui, P., Kaleem Khan, M., Tanveer, Y., Mehmood, K. and Ahmad, W. (2018), “How website quality affects online impulse buying: Moderating effects of sales promotion and credit card use”, Asia Pacific Journal of Marketing and Logistics, Vol. 30 No.1, pp. 235-256.

Al-Debei, M.M., Akroush, M.N. and Ashouri, M.I. (2015), “Consumer attitudes towards online shopping: the effects of trust, perceived benefits, and perceived web quality”, Internet Research, Vol. 25 No. 5, pp. 707-733.

Ariffin, S.K., Mohan, T. and Goh, Y.N. (2018), “Influence of consumers' perceived risk on consumers' online purchase intention”, Journal of Research in Interactive Marketing, Vol. 12 No. 3, pp. 309-327.

Babin, B.J., Darden, W.R. and Griffin, M. (1994), "Work and/or fun: measuring hedonic and utilitarian shopping value”, Journal of Consumer Research, Vol. 20 No. 4, pp. 644-656.

Batra, R. and Ahtola, O.T. (1991), "Measuring the hedonic and utilitarian sources of consumer attitudes", Marketing Letters, Vol. 2 No. 2, pp. 159-170.

Beldad, A., De Jong, M. and Steehouder, M. (2010), "How shall I trust the faceless and the intangible? A literature review on the antecedents of online trust", Computers in Human Behavior, Vol. 26 No. 5, pp. 857-869.

Benet-Martínez, V. and John, O.P. (1998), "Los Cinco Grandes across cultures and ethnic groups: multitraitmultimethod analyses of the Big Five in Spanish and English", Journal of Personality and Social Psychology, Vol. 75 No. 3, pp. 729-750.

Bilgihan, A. (2016), “Gen Y customer loyalty in online shopping: an integrated model of trust, user experience and branding", Computers in Human Behavior, Vol. 61, pp. 103-113.

Chai, J.C.Y., Malhotra, N.K. and Alpert, F. (2015), “A two-dimensional model of trust-value-loyalty in service relationships", Journal of Retailing and Consumer Services, Vol. 26, pp. 23-31. 
Chen, S.H. and Lee, K.P. (2008), "The role of personality traits and perceived values in persuasion: an elaboration likelihood model perspective on online shopping”, Social Behavior and Personality: An International Journal, Vol. 36 No. 10, pp. 1379-1399.

Chen, Y.F. and Wang, R.Y. (2016), “Are humans rational? Exploring factors influencing impulse buying intention and continuous impulse buying intention”, Journal of Consumer Behaviour, Vol. 15 No. 2, pp. 186-197.

Chiu, C.M., Wang, E.T., Fang, Y.H. and Huang, H.Y. (2014), “Understanding customers' repeat purchase intentions in $\mathrm{B} 2 \mathrm{C}$ e-commerce: the roles of utilitarian value, hedonic value and perceived risk", Information Systems Journal, Vol. 24 No. 1, pp. 85-114.

Choi, D., Oh, I.S. and Colbert, A.E. (2015), "Understanding organizational commitment: a meta-analytic examination of the roles of the five-factor model of personality and culture", Journal of Applied Psychology, Vol. 100 No. 5, pp. 1542-1567.

Cortina, J.M., Chen, G. and Dunlap, W.P. (2001), “Testing interaction effects in LISREL: examination and illustration of available procedures", Organizational Research Methods, Vol. 4 No. 4, pp. 324-360.

Costa, P.T. Jr and McCrae, R.R. (1992), "Four ways five factors are basic", Personality and Individual Differences, Vol. 13 No. 6, pp. 653-665.

Crites, S.L. Jr., Fabrigar, L.R. and Petty, R.E. (1994), “Measuring the affective and cognitive properties of attitudes: conceptual and methodological issues", Personality and Social Psychology Bulletin, Vol. 20 No. 6, pp. 619-634.

Cronbach, L.J. (1987), "Statistical tests for moderator variables: flaws in analyses recently proposed”, Psychological Bulletin, Vol. 102 No. 3, pp. 414-417.

Dabholkar, P.A., van Dolen, W.M. and de Ruyter, K. (2009), “A dual-sequence framework for B2C relationship formation: moderating effects of employee communication style in online group chat”, Psychology \& Marketing, Vol. 26 No. 2, pp. 145-174. 
Diener, E.D., Emmons, R.A., Larsen, R.J. and Griffin, S. (1985), “The satisfaction with life scale”, Journal of Personality Assessment, Vol. 49 No. 1, pp. 71-75.

Ekici, A., Sirgy, M.J., Lee, D.J, Grace, B.Y. and Bosnjak, M. (2018), “The effects of shopping well-being and shopping ill-being on consumer life satisfaction”, Applied Research in Quality of Life, Vol. 13 No. 2, pp. 333-353.

El Hedhli, K., Chebat, J.C. and Sirgy, M.J. (2013), “Shopping well-being at the mall: construct, antecedents, and consequences", Journal of Business Research, Vol. 66 No. 7, pp. 856-863.

El Hedhli, K., Zourrig, H. and Chebat, J.C. (2016), "Shopping well-being: is it just a matter of pleasure or doing the task? The role of shopper's gender and self-congruity”, Journal of Retailing and Consumer Services, Vol. 31 July, pp. 1-13.

Fornell, C. and Larcker, D.F. (1981), "Evaluating structural equation models with unobservable variables and measurement error", Journal of Marketing Research, Vol. 18 No. 1, pp. 39-50.

Giovanis, A. and Athanasopoulou, P. (2017), "Gen Y-ers' brand loyalty drivers in emerging devices”, Marketing Intelligence \& Planning, Vol. 35 No. 6, pp. 805-821.

Ha, H.Y., John, J., John, J.D. and Chung, Y.K. (2016), “Temporal effects of information from social networks on online behavior: the role of cognitive and affective trust”, Internet Research, Vol. 26 No. 1, pp. 213-235.

Ha, H.Y., Janda, S. and Muthaly, S.K. (2010), “A new understanding of satisfaction model in e-re-purchase situation”, European Journal of Marketing, Vol. 44 No. 7/8, pp. 997-1016.

Herbst, K.C., Gaertner, L. and Insko, C.A. (2003), "My head says yes but my heart says no: cognitive and affective attraction as a function of similarity to the ideal self', Journal of Personality and Social Psychology, Vol. 84 No. 6, pp. 1206-1219.

Hirschman, E.C. and Holbrook, M.B. (1982), "Hedonic consumption: emerging concepts, methods and propositions", Journal of Marketing, Vol. 46 No. 3, pp. 92-101. 
Hofmann, W., Friese, M. and Strack, F. (2009), "Impulse and self-control from a dual-systems perspective", Perspectives on Psychological Science, Vol. 4 No. 2, pp. 162-176.

Homer, P.M. and Kahle, L.R. (1988), “A structural equation test of the value-attitude-behavior hierarchy”, Journal of Personality and Social Psychology, Vol. 54 No. 4, pp. 638-646.

Hsu, C.L, Chang, K.C. and Chen, M.C. (2012), "The impact of website quality on customer satisfaction and purchase intention: perceived playfulness and perceived flow as mediators", Information Systems and e-Business Management, Vol. 10 No. 4, pp. 549-570.

Johnson, D. and Grayson, K. (2005), “Cognitive and affective trust in service relationships”, Journal of Business Research, Vol. 58 No. 4, pp. 500-507.

Kesari, B. and Atulkar, S. (2016), "Satisfaction of mall shoppers: a study on perceived utilitarian and hedonic shopping values”, Journal of Retailing and Consumer Services, Vol. 31 July, pp. 22-31.

Kim, G. and Koo, H. (2016), "The causal relationship between risk and trust in the online marketplace: a bidirectional perspective", Computers in Human Behavior, Vol. 55 February, pp. 1020-1029.

Kim, H.W., Xu, Y. and Gupta, S. (2012), "Which is more important in internet shopping, perceived price or trust?”, Electronic Commerce Research and Applications, Vol. 11 No. 3, pp. 241-252.

Kim, Y. and Peterson, R.A. (2017), “A meta-analysis of online trust relationships in e-commerce”, Journal of Interactive Marketing, Vol. 38, pp. 44-54.

Lee, D.J. and Sirgy, M.J. (2004), “Quality-of-life (QOL) marketing: proposed antecedents and consequences", Journal of Macromarketing, Vol. 24 No. 1, pp. 44-58.

Liao, C., To, P.L, Wong, Y.C., Palvia, P. and Kakhki, M.D. (2016), “The impact of presentation mode and product type on online impulse buying decisions", Journal of Electronic Commerce Research, Vol. 17 No. 2, pp. 153-168.

Lindell, M.K. and Whitney, D.J. (2001), “Accounting for common method variance in cross-sectional research designs", Journal of Applied Psychology, Vol. 86 No. 1, pp. 114-121. 
Mansour, K.B., Kooli, K. and Utama, R. (2004), “Online trust antecedents and their consequences on purchase intention: an integrative approach", Journal of Customer Behavior, Vol. 13 No. 1, pp. 25-42.

McAllister, D.J. (1995), “Affect- and cognition-based trust as foundations for interpersonal co-operation in organizations", Academy of Management Journal, Vol. 38 No. 1, pp. 24-59.

McCole, P., Ramsey, E. and Williams, J. (2010), "Trust considerations on attitudes towards online purchasing: the moderating effect of privacy and security concerns", Journal of Business Research, Vol. 63 No. 9-10, pp. 1018-1024.

Menidjel, C., Benhabib, A. and Bilgihan, A. (2017), "Examining the moderating role of personality traits in the relationship between brand trust and brand loyalty", Journal of Product \& Brand Management, Vol. 26 No. 6, pp. 631-649.

Morrow, J.L. Jr, Hansen, M.H. and Pearson, A.W. (2004), “The cognitive and affective antecedents of general trust within cooperative organizations", Journal of Managerial Issues, Vol. 16 No. 1, pp. 4864.

Nicholson, N., Soane, E., Fenton-O’Creevy, M. and Willman, P. (2005), “Personality and domain-specific risk taking”, Journal of Risk Research, Vol. 8 No. 2, pp. 157-176.

Overby, J.W. and Lee, E.J. (2006), “The effects of utilitarian and hedonic online shopping value on consumer preference and intention”, Journal of Business Research, Vol. 59, pp. 1160-1166.

Pavot, W. and Diener, E. (2008), "The satisfaction with life scale and the emerging construct of life satisfaction", The Journal of Positive Psychology, Vol. 3 No.2, pp. 137-152.

Podsakoff, P.M., MacKenzie, S.B., Lee, J.Y. and Podsakoff, N.P. (2003), "Common method biases in behavioral research: a critical review of the literature and recommended remedies", Journal of Applied Psychology, Vol. 88 No. 5, pp. 879-903.

Punyatoya, P. (2019), "Effects of cognitive and affective trust on online customer behavior", Marketing Intelligence \& Planning, Vol. 37 No. 1, pp. 80-96. 
Sarkar, A., Sarkar, J.G., Sreejesh, S. and Anusree, M.R. (2018), “A qualitative investigation of e-tail brand affect”, Marketing Intelligence \& Planning, Vol. 36 No. 3, pp. 365-380.

Sirgy, M. J., Lee, D. J., Grace, B. Y., Gurel-Atay, E., Tidwell, J., \& Ekici, A. (2016), “Self-expressiveness in shopping”, Journal of Retailing and Consumer Services, Vol. 30 May, pp 292-299.

Ul Islam, J., Rahman, J. and Hollebeek, L.D. (2017), "Personality factors as predictors of online consumer engagement: An empirical investigation”, Marketing Intelligence \& Planning, Vol. 35 No. 4, pp. 510528.

Varshneya, G., Das, G. and Khare, A. (2017), "Experiential value: a review and future research directions", Marketing Intelligence \& Planning, Vol. 35 No. 3, pp. 339-357.

Vietnam E-business Index (2018), “Vietnam e-business index EBI 2018”, available at: http://www.vecom.vn/tai-lieu/tai-lieu-trong-nuoc/bao-cao-chi-so-thuong-mai-dien-tu-viet-nam-2018 (accessed February 15, 2019).

Voss, K.E., Spangenberg, E.R. and Grohmann, B. (2003), "Measuring the hedonic and utilitarian dimensions of consumer attitude”, Journal of Marketing Research, Vol. 40 No. 3, pp. 310-320.

Watson, D. and Clark, L.A. (1997), “Extraversion and its positive emotional core”, in Hogan, R., Johnson, J. and Briggs, S. (Eds), Handbook of Personality Psychology, Academic Press, San Diego, CA, pp. 767-793.

Watson, D., Clark, L.A. and Tellegen, A. (1988), "Development and validation of brief measures of positive and negative affect: the PANAS scales", Journal of Personality and Social Psychology, Vol. 54 No. 6, pp. 1063-1070. 